\title{
Side rooms on the medical assessment unit - safety versus privacy and dignity
}

\author{
Authors: Neelesh Mohan, Wasim Mir, Sarbjit Clare, Paul Mawer
}

\section{Aims}

To assess if patients have been appropriately allocated to side rooms on the acute medical unit (AMU), along with how this impacted the workings of the AMU with a $25 \%$ side room capacity, in contradiction to current Derpartment of Health guidance of having $50-100 \%$ side room capacity.

\section{Methods}

A sequential audit over a 5-year period was completed with four side room criteria, with allocation guidance being made available on the ward between each audit.

1 Appropriate and required.

2 Appropriate but not required.

3 Inappropriate but required.

4 Inappropriate and not required

Results

$\begin{array}{llll} & \mathbf{2 0 1 1} & \mathbf{2 0 1 2} & \mathbf{2 0 1 5} \\ \text { Appropriate and required } & 19 \% & 16 \% & 21 \% \\ \text { Appropriate and not required } & 37 \% & 34 \% & 25 \% \\ \text { Inappropriate and required } & 10 \% & 15 \% & 19 \% \\ \text { Inappropriate and not required } & 34 \% & 35 \% & 35 \%\end{array}$

The first audit demonstrated the following incidents as soon as a consultant reviewed side room patients:

Two patients were moved to CCU, five patients were moved to monitored beds on MAU.

\section{Conclusions}

We feel that the aims of this project were justified and showed that, despite repeated recommendations, patients still not being allocated appropriately to side rooms. This was potentially leading to adverse events with these patients. Our opinion is that guidance of wards requiring $50-100 \%$ single occupancy rooms should not apply to AMU when designing future hospitals.

Authors: Sandwell and West Birmingham Hospitals NHS Trust, Birmingham, UK 